\title{
Icariin affects cell cycle progression and proliferation of human retinal pigment epithelial cells via enhancing expression of $\mathrm{H} 19$
}

\author{
Yibing Zhang ${ }^{\text {Corresp., } 1}$, Min $\mathbf{L i}^{2}$, Xue Han ${ }^{1}$ \\ 1 Department of Ophthalmology, The First Hospital of Jilin University, Changchun, China \\ 2 Department of Pharmacology and Toxicology, Jilin University School of Pharmaceutical Sciences, Changchun, China \\ Corresponding Author: Yibing Zhang \\ Email address: zhangyibing220@jlu.edu.cn
}

Background: Aberrant proliferation of retinal pigment epithelial (RPE) cells under pathologic condition results in the occurrence of proliferative vitreoretinopathy (PVR). Icariin-a flavonol glucoside-has been shown to inhibit proliferation of many cell types, but the effect on RPE cells is unknown. This study aimed to clarify the inhibitory effects of icariin on RPE cells against platelet-derived growth factor (PDGF)-BB-induced cell proliferation, and discuss the regulatory function of H19 in RPE cells. Methods: MTS assay was conducted to determine the effects of icariin on cell proliferation. Flow cytometry analysis was performed to detect cell cycle progression. Quantitative Real-time PCR (qPCR) and western blot assay were used to measure the expression patterns of genes in RPE cells. Results: Icariin significantly suppressed PDGF-BB-stimulated RPE cell proliferation in a concentration-dependent manner. Moreover, since administration of icariin induced cell cycle G0/G1 phase arrest, the anti-proliferative activity of icariin may be due to G0/G1 phase arrest in RPE cells. At molecular levels, cell cycle regulators cyclin D1, CDK4, CDK6, p21 and p53 were modulated in response to treatment with icariin. Most importantly, H19 was positively regulated by icariin, and $\mathrm{H} 19$ depletion could reverse the inhibitory effects of icariin on cell cycle progression and proliferation in PDGF-BB-stimulated RPE cells. Further mechanical explorations showed that $\mathrm{H} 19$ knockdown resulted in alternative expressions levels of cyclin D1, CDK4, CDK6, p21 and p53 under icariin treatment. Conclusions: Our findings revealed that icariin was an effective inhibitor of PDGF-BBinduced RPE cell proliferation through affecting the expression levels of cell cycleassociated factors, and highlighted the potential application of icariin in PVR therapy. H19 was described as a target regulatory gene of icariin whose disruption may contribute to excessive proliferation of RPE cells, suggesting that modulation of H19 expression may be a novel therapeutic approach to treat PVR. 
$1 \quad$ Icariin affects cell cycle progression and proliferation of human retinal pigment epithelial cells via enhancing expression of H19

3 Yibing Zhang ${ }^{1}$, Min $\mathrm{Li}^{2}$, Xue Han ${ }^{1}$

4 Department of Ophthalmology, The First Hospital of Jilin University, Changchun, China.

5 Department of Pharmacology and Toxicology, Jilin University School of Pharmaceutical Sciences,

6 Changchun, 130021, China.

7 Department of Ophthalmology, The First Hospital of Jilin University, Changchun, China.

8 Corresponding Author:

9 Yibing Zhang ${ }^{1}$

1071 Xinmin Ave, Changchun, 130021, China.

11 Email: zhangyibing220@jlu.edu.cn 


\section{Abstract}

14 Background: Aberrant proliferation of retinal pigment epithelial (RPE) cells under pathologic condition results in the occurrence of proliferative vitreoretinopathy (PVR). Icariin-a flavonol glucoside-has been shown to inhibit proliferation of many cell types, but the effect on RPE cells is unknown. This study aimed to clarify the inhibitory effects of icariin on RPE cells against platelet-derived growth factor (PDGF)-BB-induced cell proliferation, and discuss the regulatory function of H19 in RPE cells.

Methods: MTS assay was conducted to determine the effects of icariin on cell proliferation. Flow cytometry analysis was performed to detect cell cycle progression. Quantitative Real-time PCR (qPCR) and western blot assay were used to measure the expression patterns of genes in RPE cells.

Results: Icariin significantly suppressed PDGF-BB-stimulated RPE cell proliferation in a concentrationdependent manner. Moreover, since administration of icariin induced cell cycle G0/G1 phase arrest, the antiproliferative activity of icariin may be due to G0/G1 phase arrest in RPE cells. At molecular levels, cell cycle regulators cyclin D1, CDK4, CDK6, p21 and p53 were modulated in response to treatment with icariin. Most importantly, H19 was positively regulated by icariin, and H19 depletion could reverse the inhibitory effects of icariin on cell cycle progression and proliferation in PDGF-BB-stimulated RPE cells. Further mechanical explorations showed that H19 knockdown resulted in alternative expressions levels of cyclin D1, CDK4, CDK6, p21 and p53 under icariin treatment.

Conclusions: Our findings revealed that icariin was an effective inhibitor of PDGF-BB-induced RPE cell proliferation through affecting the expression levels of cell cycle-associated factors, and highlighted the potential application of icariin in PVR therapy. H19 was described as a target regulatory gene of icariin whose expression may be a novel therapeutic approach to treat PVR. 


\section{Introduction}

Proliferative vitreoretinopathy (PVR), a defective wound repair process responding to either retinal detachment or vitreoretinal surgery, is a severe blinding disease due to the recurrent epiretinal membranes (ERMs) traction [1]. PVR is characterized by proliferation of cells and contraction of membranes within the vitreous cavity and on both sides of the retinal surfaces, which is a common cause of failure in rhegmatogenous retinal detachment surgery [2]. Many attempts have been made in PVR pharmacotherapy [3, 4], but there are not ideal drugs for PVR treatment because the molecular mechanisms underlying PVR are not well understood. Pathogenesis of PVR is a complex biological process regulated by multiple growth factors and cytokines [5], and the retinal pigment epithelium (RPE) cells are considered as the key cell type in PVR, which is deemed to proliferate and migrate through retinal breaks $[6,7]$. Among the growth factors, plateletderived growth factor (PDGF)-induced RPE cell proliferation is an important step for promoting fibrotic membrane formation in PVR development [8]. There are four PDGF isoforms (PDGF-A, -B, -C, and -D) that form homodimers or heterodimers (PDGF-AA, -BB, AB, -CC, and -DD) through disulfide bonds. Moreover, PDGF-B shows extensively proliferative effects on RPE cells [9-12]. Since the proliferation of activated RPE cells is believed to be a central event in the pathogenesis of PVR, it is vital to identify specific drug targets whose modulation can block the uncontrolled proliferation of RPE cells.

Icariin (ICA) (molecular formula: $\mathrm{C}_{33} \mathrm{H}_{40} \mathrm{O}_{15}$; molecular weight: $676.67 \mathrm{~g} / \mathrm{mol}$ ), the main active ingredient of the traditional Chinese medical plant Herba Epimedii, has a wide range of pharmacological and biological activities, such as possessing anti-oxidative, anti-tumor, and anti-inflammatory activities [13-15]. Recently, emerging studies have reported ICA regulates cell cycle progression and proliferation in various cell types. ICA exerted suppressive effects on medulloblastoma cells [16], osteosarcoma cells [17] and human aortic smooth muscle cells (HA-VSMCs) [18]. Further, the induction of G0/G1 phase arrest was observed in cardiomyocyte and breast cancer cells after treatment with ICA $[19,20]$. However, whether ICA could modulate cell cycle progression and proliferation in RPE cells remains largely unclear.

Long noncoding RNAs (lncRNAs) are transcripts with a length $>200$ nucleotides structurally homologous to coding mRNAs, but has little or no protein-coding potential [21]. LncRNAs can modulate gene expression and are implicated in diverse biological processes, such as cell differentiation, cell cycle, cell proliferation, 
63

apoptosis, migration, and stem cell maintenance [22]. Dysregulation of lncRNAs is found involved in multiple human diseases such as cancer, cardiovascular diseases, and neurological problems [23-27]. Roles of lncRNAs in ocular disorders, such as ocular tumors, diabetic retinopathy (DR), PVR, cataract and glaucoma, have also been identified [28]. Moreover, as one of the best-characterized lncRNAs with multiple functions, H19 has been closely associated with the pathogenesis of ocular diseases in recent studies [29-31]. Nevertheless, the effect of H19 on cell cycle and proliferation in RPE cells is still uninvestigated.

In this study, we found that ICA treatment could significantly cause delays at the G1-S transition and inhibit RPE cell proliferation upon the stimulus of PDGF-BB, which may be realized by affecting the expression of cell cycle-related genes, such as cyclin D1, cyclin-dependent kinase 4 (CDK4), CDK6, CDK inhibitor 1A (p21), and p53. We further explored the biological function of H19 which might contribute to the inhibitory effect of ICA, describing an experimental basis for investigating H19 as a potential therapeutic target for PVR. Our findings highlighted the anti-proliferative effects of ICA, as well as determined the potential influences of H19 in RPE cells, providing a new perspective for the treatment of PVR.

\section{Materials and methods}

\section{Cell culture}

ARPE-19 cells were purchased from American Type Culture Collection (ATCC, Manassas, VA, USA) and maintained in DMEM/F12 medium (Invitrogen, Carlsbad, CA, USA) supplemented with 10\% FBS, 100 $\mathrm{U} / \mathrm{ml}$ penicillin and $100 \mathrm{mg} / \mathrm{ml}$ streptomycin (all from Invitrogen) at $37{ }^{\circ} \mathrm{C}$ in a humidified atmosphere with $5 \% \mathrm{CO}_{2}$.

\section{Cell treatment and transfection}

ICA (Vic's Biological Technology Co., Ltd, Sichuan, China) was dissolved in DMSO (Sigma-Aldrich, St Louis, MO, USA) and stocked at $100 \mathrm{mM}$, which was diluted to the desired concentrations with culture medium. When tested, ICA was added 30 min prior to PDGF-BB $(20 \mathrm{ng} / \mathrm{ml}$; Selleck Chemicals, Houston, TX, USA) stimulation.

Small interfering RNA oligonucleotides targeting H19 (si-H19) was obtained from Ribobio Biotechnology (Guangzhou Ribobio Co., Ltd, Guangzhou, China). The scrambled siRNA (si-NC) was used as 
89

90

91

a negative control. RPE cells were transfected with si-H19 or si-NC by using Lipofectamine 2000 reagent (Invitrogen, Carlsbad, CA, USA) following the manufacturer's protocol. After transfected for $48 \mathrm{~h}$, cells were harvested for the following experiment and divided into five groups: (1) blank control group without PDGFBB; (2) PDGF-BB-stimulated group (with PDGF-BB $20 \mathrm{ng} / \mathrm{ml}$ only); (3) PDGF-BB+ICA treatment group (with PDGF-BB and ICA); (4) PDGF-BB+ICA+si-NC treatment group (with PDGF-BB, ICA and si-NC); (5) PDGF-BB+ICA+si-H19 treatment group (with PDGF-BB, ICA and si-H19).

\section{MTS assay}

RPE cells were cultured in 96-well plate at a density of $1 \times 10^{4}$ cells/well, and incubated for $24 \mathrm{~h}$ under 5\% $\mathrm{CO}_{2}$ at $37{ }^{\circ} \mathrm{C}$. After different treatments, these cells were collected at each time point $(0,24,48$ or $72 \mathrm{~h})$. Cell proliferation was then assessed by the colorimetric MTS[(3-(4,5-dimethylthiazol-2-yl)-5-(3carboxymethoxyphenyl)-2-(4-sulfophenyl)-2H-tetrazolium] reduction method (Cell Titer 96®Aqueous One Solution Reagent; Promega, Madison, WI, USA) following the manufacturer's instructions. The absorbance was measured at $490 \mathrm{~nm}$ with a microplate reader (Thermo Fisher, Waltham, MA, USA).

\section{Flow cytometry analysis}

The cell cycle distribution of RPE cells was estimated using a flow cytometer by quantitation of DNA content of cells stained with propidium iodide (PI). In brief, RPE cells were seeded on 6-cm dishes and harvested after $48 \mathrm{~h}$. Then cells were fixed overnight at $4{ }^{\circ} \mathrm{C}$ with $70 \%$ ethanol, followed by resuspension in $500 \mu \mathrm{l}$ of PBS. Fixed cells were incubated in PBS containing PI and RNase A for at least 30 min at $4{ }^{\circ} \mathrm{C}$. Cellular DNA content was analyzed on a BD FACSCalibur (Becton Dickinson, San Jose, CA, USA). Data was analyzed with ModFit LT 3.0 software (Variety Software House, Inc., Topsham, ME, USA).

\section{Quantitative Real-time PCR (qPCR)}

Total RNA was isolated from RPE cells using TRIzol reagent (Invitrogen, Carlsbad, CA, USA) and transcribed into cDNA using an ImProm-IITM Reverse Transcription System (Promega, Madison, WI, USA) according to the protocol provided by the manufacturer. Quantitaitve PCR was performed using SYBR GREEN qPCR Super Mix (Invitrogen, Carlsbad, CA, USA) in a 7500 Real-Time PCR system (Applied Biosystems, Carlsbad, CA, USA). The $2^{(-\Delta \Delta C t)}$ method was used to quantify the relative mRNA expression 
115 changes [32], using GAPDH as an internal control. All forward and reverse primers were synthesized by

116 Sangon Biotech (Sangon Biotech Co., Ltd, Shanghai, China) and are indicated in Table 1.

117 Western blot analysis

118 RPE cells were collected and lysed in radio-immunoprecipitation (RIPA) buffer (Beyotime

119 Biotechnology Co., Ltd, Shanghai, China), and then centrifuged at $14000 \mathrm{rpm}$ for $10 \mathrm{~min}$ at $4{ }^{\circ} \mathrm{C}$. The protein

120 concentration of the supernatants was determined using the BCA protein assay (KeyGEN Biotech Co., Ltd,

121 Nanjing, China). Total proteins were separated by electrophoresis on 10\% SDS-polyacrylamide gels, and the

122 proteins were electroblotted onto polyvinylidene fluoride (PVDF) membranes (Millipore, Billerica, MA, USA).

123 After blocking with 5\% skimmed milk for $1 \mathrm{~h}$ at room temperature, the membranes were incubated with

124 primary antibodies against p53 (diluted at 1: 1000, ab131442), p21 (diluted at 1: 1000, ab109520), CDK4

125 (diluted at 1: 1000, ab108357), CDK6 (diluted at 1: 1000, ab124821), cyclinD1 (diluted at 1: 1000, ab134175),

126 and GAPDH (1: 1000, ab181602; all from Abcam, San Diego, MA, USA) at $4{ }^{\circ} \mathrm{C}$ overnight. After being

127 incubated with horseradish peroxidase-conjugated secondary antibodies for $1 \mathrm{~h}$ at $37^{\circ} \mathrm{C}$, the membranes were

128 developed with chemiluminescence substrate (Millipore, Billerica, MA, USA) and quantified with Image J

129 system (BioRad, Hercules, CA, USA).

130 Statistical analysis

131 All quantitative data were presented as mean \pm standard deviation (SD). At least three independent 132 experiments were done. All statistical parameters were calculated with GraphPad Prism 8.0 (GraphPad 133 Software Inc.). Student's $t$ test was used to analyze the difference between two groups. One-way ANOVA 134 followed by post-hoc test with least significant difference (LSD) was performed to evaluate differences among 135 multiple groups. $\mathrm{P}<0.05$ was considered statistically significant.

136

137

138

139

140

\section{Results}

\section{ICA decreased viability of RPE cells in a concentration-dependent manner}

The inhibitory effect of ICA on the RPE cells without stimulation of PDGF-BB was detected via MTS assay initially. ICA concentrations were set as $1,5,10,20,40$ and $80 \mu \mathrm{M}$, and the blank control were established. Compared with control group, we found that ICA treatment significantly decreased the viability 
141

142

143

144

145

146

147

radio of RPE cells in a concentration-dependent manner, the half maximal inhibitory concentration (IC50) value of ICA was $19.36 \mu \mathrm{M}$ (Fig. 1A).

Moreover, the effect of ICA on PDGF-BB-stimulated proliferation of RPE cells was tested with increasing concentration of ICA $(10$ to $40 \mu \mathrm{M})$ and the rate of proliferation was calculated. The results were shown in Table 2 and Fig. 1B. As compared with blank control group, the absorbance in RPE cells was significantly enhanced by PDGF-BB stimulation for 24 to $72 \mathrm{~h}$; contrarily, we observed that ICA showed concentration-dependent anti-proliferative activity in RPE cells.

\section{ICA induced cell cycle G0/G1 phase arrest in PDGF-BB-stimulated RPE cells}

We used flow cytometer analysis to test the effect of ICA on cell cycle progression. ICA-induced inhibition of RPE cell proliferation was associated with G0/G1 arrest. The proportion of RPE cells in the G0/G1 phase was significantly lower in the PDGF-BB-stimulated group than in the control group. After the RPE cells were incubated with ICA $(10,20$ and $40 \mu \mathrm{M})$ for $48 \mathrm{~h}$, the total percentage of RPE cells in G0/G1 phase increased, significantly when concentration of ICA reached $40 \mu \mathrm{M}(\mathrm{p}<0.001$ vs. PDGF-BB group), suggesting that ICA delayed the G1/S phase transition (Fig. 2).

\section{ICA affected the expression levels of cell cycle regulators in RPE cells}

Results in Fig. 1-2 displayed that ICA remarkably suppressed cell cycle progression and proliferation of RPE cells when its concentrations was $40 \mu \mathrm{M}$. Therefore, $40 \mu \mathrm{M}$ ICA was used to treat RPE cells in the following experiment. The expression levels of cell cycle regulators (CDK4, CDK6, cyclin D1, p21, and p53) were further evaluated by qPCR and western blot. After $48 \mathrm{~h}$ of stimulation with PDGF-BB, it was found that the mRNA levels of p53 and p21 were decreased, while showed increase in CDK4, CDK6, and cyclin D1. Consistently with G0/G1 arrest, ICA increased the mRNA levels of p53 and p21, while reduced the mRNA levels of CDK4, CDK6, and cyclin D1 (Fig. 3A). At protein levels, p53 and p21 were also decreased after PDGF-BB stimulation, while CDK4, CDK6, and cyclin D1 were increased (Fig. 3B-C). Comparatively, the protein levels of p53 and p21 were increased in response to treatment with ICA in PDGF-BB-stimulated RPE cell. Likewise, CDK4, CDK6, and cyclin D1 were significantly reduced at protein levels.

\section{ICA enhanced the expression level of H19 in PDGF-BB-stimulated RPE cells}


The RPE cells were treated with different concentrations of ICA and then exposed to PDGF-BB stimulation, after which qPCR was undertaken. The results showed that H19 expression level was significantly down-regulated by PDGF-BB, ICA could increase the expression level of H19 in a concentration-dependent manner (Fig. 4).

\section{ICA inhibited the PDGF-BB-stimulated cell proliferation via enhancing the expression of H19}

Afterward, si-H19 and si-NC were transfected into RPE cells, and the transfected efficiency was presented in Fig. 5A. The expression level of H19 was markedly down-regulated in si-H19-transfected cells compared with that in si-NC-transfected cells. The data indicated that si-H19 was successfully transfected into RPE cells to inhibit H19 expression.

Down-regulation of $\mathrm{H} 19$ could partially reverse the inhibition of cell proliferation induced by ICA treatment in RPE cells (Fig. 5B-C). Subsequently, the increased percentage of cell cycle distribution after ICA treatment was significantly reduced by H19 knockdown (Fig. 5D-E).

ICA affected expression levels of cell cycle regulators in PDGF-BB-stimulated RPE cells via enhancing the expression of $\mathrm{H19}$

Finally, expressions of cell cycle-related factors were determined to clarify the suppressive effects of ICA on cell proliferation via enhancing the expression level of H19. As shown in Fig. 6A, H19 knockdown decreased the mRNA levels of p53 and p21 in ICA-treated RPE cells, meanwhile, H19 knockdown reversed the reducing effects of ICA on mRNA levels of CDK4, CDK6, and cyclin D1. Consistently, si-H19 transfection dramatically reversed the regulatory effect of ICA on p53, p21 CDK4, CDK6, and cyclin D1 expression at protein levels (Fig. 6B-C). Collectively, these results strongly supported that ICA could modulate the expressions of cell cycle-associated proteins by increasing the expression level of H19 in PDGF-BBstimulated RPE cells.

\section{Discussion}

RPE cells play diverse critical roles in visual function and eye development, they are highly specialized monolayer cells and form the blood-retinal barrier between the light-sensitive outer segments of the photoreceptors and choroidal vasculature. Excessive proliferation of RPE cells is triggered by specific 
193

194

196

197

198

199

200

201

202

203

204

205

206

207

inflammatory cytokines and growth factors. PDGF has been implicated in vascular proliferative retinopathies, such as diabetic retinopathy (DR), and in nonvascular retinopathies, such as PVR [33]. Moreover, cumulative studies have shown that PDGF-BB is a major mitogen for RPE cell proliferation and directly resulted in the development of PVR. Mori and colleagues generated hemizygous rhodopsin promoter/PDGF-B (rho/PDGF-B) transgenic mice with retina-specific expression of PDGF-B, high retinal expression of PDGF-B results in elevated proliferation of RPE cells and traction retinal detachment [34]. Additionally, Akiyama, et al. observed that intravitreous injections of anti-PDGF-B aptamers significantly suppressed retinal detachment and ERMs formation in rho/PDGF-B transgenic mice [35]. Several intracellular signal cascades activated by PDGF-BB have been verified to play key roles in regulating of RPE cell proliferation. The PI3K/Akt and MAPK pathways have been shown to be involved in the mechanisms of various cells proliferation, of which RPE cells are regarded as the predominant target [10-11]. Zhang et al. reported that PDGF-BB induces RPE proliferation via PDGF receptor and its downstream component PI3K/Akt pathway, while ERK1/2, p38 and JNK signals are modulated to control the progression of cell cycle [10]. In line with the findings, Li et al. demonstrated that miR-27b promoted RPE cell proliferation by inhibiting PI3K/Akt/mTOR pathway [11]. Hence, we chose to conduct the recent experiment with PDGF-BB, providing a simulated pathologic condition for RPE cells.

Recent efforts have been directed toward the biochemical inhibition of cellular proliferation in PVR, but the effect is not ideal. ICA is a pharmacologically active flavonoid that can suppress growth and promote apoptosis in a variety of malignant cells $[16,17]$. Additionally, ICA prevents against mitogen-induced aberrant proliferation in other cell lines. A prior study found that ICA treatment evidently ameliorated angiotensin II (Ang II)-induced cell proliferation in human brain vascular SMCs (HB-VSMCs) [36]. Meanwhile, our colleagues demonstrated that oxidized low density lipoprotein (ox-LDL) significantly increases cell viability of HA-VSMCs, yet ICA suppressed ox-LDL-induced HA-VSMC proliferation in a concentration-dependent manner [18]. Previous studies have clearly demonstrated that ox-LDL can promote cell proliferation via activating platelet-derived growth factor receptor- $\beta$ (PDGFR- $\beta$ )pathway [37]. These evidences suggested that ICA affects cell proliferation probably through the inhibition of PDGFR- $\beta$ activation. ICA has been widely used to treat various diseases such as cardiovascular disease, osteoporosis, and rheumatoid arthritis [13-15], while it was reported that ICA attenuates streptozotocin (STZ)-induced DR conditions depending upon 
220

221

222

223

224

225

226

227

228

229

230

231

232

233

234

235

236

237

238

239

240

241

242

243

244

245

246

concentrations both in vitro and in vivo [38]. Comparatively, whether ICA could affect cell cycle progression and proliferation in RPE cells remain unknown. Therefore, it gives us interest to explore the effect of ICA on PDGF-BB-stimulated RPE cell behaviors.

LncRNAs arise more attention of ophthalmologists since they contribute to the regulation of RPE cells in various aspects [39-41]. To date, several lncRNAs have been identified to play important roles in regulating cellular proliferation and apoptosis in RPE cells [28, 42-44], such as lncRNA BDNF-AS, nuclear factor-кB (NF-кB) Interacting LncRNA (NKILA), and Metastasis Associated Lung Adenocarcinoma Transcript 1 (MALAT1). MALAT1 is one of the best-defined lncRNAs with many functions. Yang et al. confirmed that knockdown of MALAT1 significantly hampered the proliferation of RPE cells after treated with transforming growth factor $\beta 1$ (TGF- $\beta 1$ ) [44]. Likewise, Zhou et al. reported the same role of MALAT1 in regulating RPE cell proliferation upon the stimulus of tumor necrosis factor $\alpha(\mathrm{TNF}-\alpha)$. MALAT1 was identified as a PVRrelated lncRNA through microarray analysis with clinical ERMs samples, the elevated MALAT1 levels in peripheral blood of PVR patients were verified also [28]. These parallel results indicated that MALAT1 might be a potential target for the diagnosis and therapy of PVR diseases.

As one of earliest identified lncRNAs, H19 is a key regulator of proliferation in multiple cells. However, the expression levels and regulatory effects on cell proliferation of H19 are discordant, even in the same cell type. For instance, Li and colleagues demonstrated that H19 exerted proapoptotic and anti-proliferative effects in HA-VSMCs leading to subsequent abdominal aortic aneurysm development. The up-regulated expression profile of H19 could also be observed in human aneurysm tissue samples. Since it has been well established that transcription factor p53 reduces cell proliferation in response to stress, molecular mechanism experiments conducted by Li et al. revealed that H19 could prevent murine double minute 2 (Mdm2)-mediated reduction of p53 via interacting with hypoxia-induced factor $1 \alpha$ (HIF1 $\alpha$ ), which in the hypoxic environment of aneurysm triggers apoptosis in HA-VSMCs [45]. Paradoxically, Zhang et al. stated that H19 depletion could induce apoptosis and suppress proliferation in ox-LDL-induced HA-VSMCs [46]. Thus, it is imperative to better understand the mechanism of H19-mediated cellular proliferation.

H19 is also highly expressed in diverse ocular cell lines. Klein et al. explored the role for cofactors of LIM domain proteins (CLIM) in regulating the proliferative potential of corneal epithelial progenitors and 
247 identified CLIM downstream target H19 as a negative regulator of corneal epithelial proliferation [29]. A

248 recent study showed the regulatory effect of H19 on endothelial-mesenchymal transition (EndMT) in

249 proliferative DR. It manifested that the expression of H19 was down-regulated either in high glucose-induced

250 retinal endothelial cells or in diabetic mice; over-expression of H19 reversed high glucose-induced EndMT

251 markers both in vitro and in vivo. Moreover, the expression level of H19 is significantly lower in the diabetic

252 vitreous humour vs healthy control [30]. Alteration of p21 expression has been reported to be an independent

253 indicator of cell proliferation in tumorigenesis [47]. Zhang et al. investigated the modulating function of H19

254 in retinoblastoma, enhanced expression of H19 could induce retinoblastoma cell cycle arrest and promote cell

255 proliferation. Their results also demonstrated that H19 could upregulate p21 expression via competitively

256 binding to miR-17-92 cluster [48].

257 As previously reported in the above ocular cell types [29, 30, 49], we observed similar negative effect of

258

259

260

261

262

263

264

265

266

267

268

269

270

271

272

273

H19 on RPE cell proliferation. Specifically, our present study found that the level of H19 was reduced upon

the stimulus of PDGF-BB in RPE cells whereas H19 expression was significantly increased with ICA

treatment. Thus, we further explored the role of H19 in RPE cells by knocking down H19 using siRNA.

Functional experiments revealed that $\mathrm{H} 19$ deletion obviously reversed the repressive action of ICA on cell cycle progression and proliferation, indicated that $\mathrm{H} 19$ might play an essential role in the anti-proliferative activity of ICA. As stated above, H19 inhibited cellular proliferation by regulating the expression levels of p53 or p21 $[45,48]$. Of note, our data confirmed the regulation of H19 acting on p53 and p21 expression in RPE cells. As one of the p53 downstream genes, p21 inhibits the activity of cyclin/CDK complex, which in turn results in cell cycle arrest. In fact, CDK4/6 plays a necessary role in the G1-S transition by associating with cyclin D and phosphorylating the retinoblastoma protein (RB) $[47,49]$. Our investigations revealed that ICA could repress the expression of CDK4, CDK6 and cyclin D1, thereby inducing G1-S arrest directly in PDGFBB-stimulated RPE cells. H19 was responsible for the observed inhibitory effect of ICA, providing a rationale for the treatment of PVR.

Despite these promising results in recent research, the understanding of H19-mediated cellular proliferation in depth is inadequate. The underling mechanisms involved in the regulatory function of H19 are complex, different roles have been described for H19 in regulating various stages of gene expression, mostly 
274

275

276

277 associated with its behavior as the precursor of miR-675 [50]. Besides the H19/miR-675 signaling axis to modulate target genes, H19 can function as competing endogenous RNAs (ceRNAs) by base-paring to and sequestering definite miRNAs [51], whereas H19 can alter mRNAs stability by interacting with specific RNA binding proteins (RBPs) [52]. It will be interesting to explore whether $\mathrm{H} 19$ can interact with partners such as miRNAs or RBPs to regulate the expression of cell proliferation-related genes in RPE cells. Further studies, which take the detailed molecular relationships into account, will need to be undertaken. Another limitation is that this present study clarified the effect of ICA on cell growth only by accessing proliferative ability of RPE cells, but the analysis on cell apoptosis was not conducted. Further verifications and reasonable analyses are still worthwhile to explore how ICA modulates RPE cell apoptosis, and the role of H19 in the ICA-mediated effect.

In summary, our work contributed to elucidating the potential target of ICA in RPE cell proliferation, hinting the probable application of ICA in preventing PVR. The finding suggested that H19 participated in the proliferation of RPE cells. ICA administration induced a G0/G1 arrest and hampered cell proliferation in PDGFBB-stimulated RPE cells, and this may depend on its positive regulation of H19 expression. Nonetheless, the exact regulatory mechanisms of $\mathrm{H} 19$ in the context of RPE cell proliferation are still indispensable to be discussed in future. 
291

292

293

294

295

296

297

298

299

300

301

302

303

304

305

306

307

308

309

310

311

312

313

314

315

316

317

318

319

320

321

322

323

324

\section{Reference}

1. Feng K, Hu Y, Wang C, Shen L, Pang X, Jiang Y, Nie H, Wang Z, Ma Z. Risk factors, anatomical, and visual outcomes of injured eyes with proliferative vitreoretinopathy: eye injury vitrectomy study. Retina. 2013;33(8):1512-8.

2. Khan MA, Brady CJ, Kaiser RS. Clinical management of proliferative vitreoretinopathy: an update. Retina. 2015;35(2):165-75.

3. Abdullatif AM, Macky TA, Abdullatif MM, Nassar K, Grisanti S, Mortada HA, Soliman MM. Intravitreal decorin preventing proliferative vitreoretinopathy in perforating injuries: a pilot study. Graefe's archive for clinical and experimental ophthalmology. 2018;256(12):2473-81.

4. Tikhonovich MV, Erdiakov AK, Gavrilova SA. Nonsteroid anti-inflammatory therapy suppresses the development of proliferative vitreoretinopathy more effectively than a steroid one. International ophthalmology. 2018;38(4):1365-78.

5. Hoerster R, Fauser S, Cursiefen C, Kirchhof B, Heindl LM. The influence of systemic renin-angiotensininhibition on ocular cytokines related to proliferative vitreoretinopathy. Graefe's archive for clinical and experimental ophthalmology. 2017;255(9):1721-5.

6. Umazume K, Tsukahara R, Liu L, Fernandez de Castro JP, McDonald K, Kaplan HJ, Tamiya S. Role of retinal pigment epithelial cell $\beta$-catenin signaling in experimental proliferative vitreoretinopathy. The American journal of pathology. 2014;184(5):1419-28

7. .Chen C, Wang JJ, Li J, Yu Q, Zhang SX. Quinotrierixin inhibits proliferation of human retinal pigment epithelial cells. Mol Vis. 2013;19:39-46.

8. Li R, Maminishkis A, Wang FE, Miller SS. PDGF-C and -D induced proliferation/migration of human RPE is abolished by inflammatory cytokines. Invest Ophthalmol Vis Sci. 2007;48(12):5722-32.

9. Chan CM, Fang JY, Lin HH, Yang CY, Hung CF. Lycopene inhibits PDGF-BB-induced retinal pigment epithelial cell migration by suppression of PI3K/Akt and MAPK pathways. Biochemical and biophysical research communications. 2009;388(1):172-6.

10. Zhang H, Shang Q, An J, Wang C, Ma J. Crocetin inhibits PDGF-BB-induced proliferation and migration of retinal pigment epithelial cells. European journal of pharmacology. 2019;842:329-37.

11. Li J, Hui L, Kang Q, Li R. Down-regulation of microRNA-27b promotes retinal pigment epithelial cell proliferation and migration by targeting Nox2. Pathology, research and practice. 2018;214(7):925-33.

12. Chan CM, Chang HH, Wang VC, Huang CL, Hung CF. Inhibitory effects of resveratrol on PDGF-BBinduced retinal pigment epithelial cell migration via PDGFR $\beta$, PI3K/Akt and MAPK pathways. PloS one. 2013;8(2):e56819.

13. Li C, Li Q, Mei Q, Lu T. Pharmacological effects and pharmacokinetic properties of icariin, the major bioactive component in Herba Epimedii. Life sciences. 2015;126:57-68. 
14. Zhang SQ, Cai WJ, Huang JH, Wu B, Xia SJ, Chen XL, Zhang XM, Shen ZY. Icariin, a natural flavonol glycoside, extends healthspan in mice. Experimental gerontology. 2015;69:226-35.

15. Fang J, Zhang Y. Icariin, an anti-atherosclerotic drug from Chinese medicinal herb Horny Goat Weed. Frontiers in pharmacology. 2017;8:734.

16. Sun Y, Sun XH, Fan WJ, Jiang XM, Li AW. Icariin induces S-phase arrest and apoptosis in medulloblastoma cells. Cellular and Molecular Biology. 2016; 62(4):123-9.

17. Ren Y, Zhu F, Liu Z. Inhibitory effect of icariin on osteosarcoma cell proliferation via the Wnt/ $\beta$-catenin signaling pathway. Oncology letters. 2018;16(2):1405-10.

18. Hu Y, Liu K, Yan M, Zhang Y, Wang Y, Ren L. Icariin inhibits oxidized low-density lipoprotein-induced proliferation of vascular smooth muscle cells by suppressing activation of extracellular signal-regulated kinase 1/2 and expression of proliferating cell nuclear antigen. Molecular medicine reports. 2016;13(3):2899-903.

19. Zhu D, Qu L, Zhang X, Lou Y. Icariin-mediated modulation of cell cycle and p53 during cardiomyocyte differentiation in embryonic stem cells. European journal of pharmacology. 2005;514(2-3):99-110.

20. Cheng X, Tan S, Duan F, Yuan Q, Li Q, Deng G. Icariin induces apoptosis by suppressing autophagy in tamoxifen-resistant breast cancer cell line MCF-7/TAM. Breast cancer. 2019.

21. Ma L, Bajic VB, Zhang Z. On the classification of long non-coding RNAs. RNA biology. 2013;10(6):92533.

22. Mercer TR, Mattick JS. Structure and function of long noncoding RNAs in epigenetic regulation. Nature structural \& molecular biology. 2013;20(3):300-7.

23. Shi X, Sun M, Liu H, Yao Y, Song Y. Long non-coding RNAs: a new frontier in the study of human diseases. Cancer letters. 2013;339(2):159-66.

24. Zhang L, Yang F, Yuan JH, Yuan SX, Zhou WP, Huo XS, Xu D, Bi HS, Wang F, Sun SH. Epigenetic activation of the MiR-200 family contributes to H19-mediated metastasis suppression in hepatocellular carcinoma. Carcinogenesis. 2013;34(3):577-86.

25. Sun TT, He J, Liang Q, Ren LL, Yan TT, Yu TC, Tang JY, Bao YJ, Hu Y, Lin Y, Sun D, Chen YX, Hong J, Chen H, Zou W, Fang JY. LncRNA GClnc1 promotes gastric carcinogenesis and may act as a modular scaffold of WDR5 and KAT2A complexes to specify the histone modification pattern. Cancer discovery. 2016;6(7):784-801.

26. Li L, Wang L, Li H, Han X, Chen S, Yang B, Hu Z, Zhu H, Cai C, Chen J, Li X, Huang J, Gu D. Characterization of IncRNA expression profile and identification of novel lncRNA biomarkers to diagnose coronary artery disease. Atherosclerosis. 2018;275:359-67.

27. Kour S, Rath PC. Age-related expression of a repeat-rich intergenic long noncoding RNA in the rat brain. Molecular neurobiology. 2017;54(1):639-60. 
28. Zhou RM, Wang XQ, Yao J, Shen Y, Chen SN, Yang H, Jiang Q, Yan B. Identification and characterization of proliferative retinopathy-related long noncoding RNAs. Biochemical and biophysical research communications. 2015;465(3):324-30.

29. Klein RH, Stephens DN, Ho H, Chen JK, Salmans ML, Wang W, Yu Z, Andersen B. Cofactors of LIM domains associate with estrogen receptor $\alpha$ to regulate the expression of noncoding RNA H19 and corneal epithelial progenitor cell function. Journal of biological chemistry. 2016;291(25):13271-85.

30. Thomas AA, Biswas S, Feng B, Chen S, Gonder J, Chakrabarti S. IncRNA H19 prevents endothelialmesenchymal transition in diabetic retinopathy. Diabetologia. 2019;62(3):517-30.

31. Liu X, Liu C, Shan K, Zhang S, Lu Y, Yan B, Luo Y. Long non-coding RNA H19 regulates human lens epithelial cells function. Cellular physiology and biochemistry. 2018;50(1):246-60.

32. Livak KJ, Schmittgen TD. Analysis of relative gene expression data using real-time quantitative PCR and the $2^{-\Delta \Delta \mathrm{Ct}}$ Method. Methods. 2001;25(4):402-8.

33. Cui J, Lei H, Samad A, Basavanthappa S, Maberley D, Matsubara J, Kazlauskas A. PDGF receptors are activated in human epiretinal membranes. Experimental eye research. 2009;88(3):438-44.

34. Mori K, Gehlbach P, Ando A, Dyer G, Lipinsky E, Chaudhry AG, Hackett SF, Campochiaro PA. Retinaspecific expression of PDGF-B versus PDGF-A: vascular versus nonvascular proliferative retinopathy. Invest Ophthalmol Vis Sci. 2002;43(6):2001-6.

35. Akiyama H, Kachi S, Silva RL, Umeda N, Hackett SF, McCauley D, McCauley T, Zoltoski A, Epstein DM, Campochiaro PA. Intraocular injection of an aptamer that binds PDGF-B: a potential treatment for proliferative retinopathies. Journal of cellular physiology. 2006;207(2):407-12.

36. Dong H, Ming S, Fang J, Li Y, Liu L. Icariin ameliorates angiotensin II-induced cerebrovascular remodeling by inhibiting Nox2-containing NADPH oxidase activation. Human cell. 2019;32(1):22-30.

37. Vindis C, Escargueil-Blanc I, Elbaz M, Marcheix B, Grazide MH, Uchida K, Salvayre R, Nègre-Salvayre A. Desensitization of platelet-derived growth factor receptor- $\beta$ by oxidized lipids in vascular cells and atherosclerotic lesions: prevention by aldehyde scavengers. Circulation research. 2006;98(6):785-92.

38. Xin H, Zhou F, Liu T, Li GY, Liu J, Gao ZZ, Bai GY, Lu H, Xin ZC. Icariin ameliorates streptozotocininduced diabetic retinopathy in vitro and in vivo. International journal of molecular sciences. 2012;13(1):866-78.

39. Kutty RK, Samuel W, Duncan T, Postnikova O, Jaworski C, Nagineni CN, Redmond TM. Proinflammatory cytokine interferon- $\gamma$ increases the expression of BANCR, a long non-coding RNA, in retinal pigment epithelial cells. Cytokine. 2018;104:147-50.

40. Ye Z, Li Z, He S. Long noncoding RNA associatedcompeting endogenous RNAs are induced by clusterin in retinal pigment epithelial cells. Molecular medicine reports. 2017;16(6):8399-405.

41. Chen X, Jiang C, Qin B, Liu G, Ji J, Sun X, Xu M, Ding S, Zhu M, Huang G, Yan B Zhao C. LncRNA ZNF503-AS1 promotes RPE differentiation by downregulating ZNF503 expression. Cell death \& disease. 
2017;8(9):e3046.

42. Li Y, Xu F, Xiao H, Han F. Long noncoding RNA BDNF-AS inversely regulated BDNF and modulated high-glucose induced apoptosis in human retinal pigment epithelial cells. Journal of cellular biochemistry. 2018;119(1):817-23.

43. Zhou Q, Zhou L, Qian J, Yuan ZL, Chen ZJ. NKILA inhibition protects retinal pigment epithelium cells from hypoxia by facilitating NF- $\mathrm{KB}$ activation. Biochemical and biophysical research communications. 2018;503(4):3134-41.

44. Li T, Yang S, Yao H, Li M, Li H, Wang F. Long non-coding RNA MALAT1 mediates transforming growth factor $\beta 1$-induced epithelial-mesenchymal transition of retinal pigment epithelial cells. PloS one. 2016;11(3):e0152687.

45. Li DY, Busch A, Jin H, Chernogubova E, Pelisek J, Karlsson J, Sennblad B, Liu S, Lao S, Hofmann P, Bäcklund A, Eken SM, Roy J, Eriksson P, Dacken B, Ramanujam D, Dueck A, Engelhardt S, Boon RA, Eckstein HH, Spin JM, Tsao PS, Maegdefessel L. H19 Induces Abdominal Aortic Aneurysm Development and Progression. Circulation. 2018;138(15):1551-68.

46. Zhang L, Cheng H, Yue Y, Li S, Zhang D, He R. H19 knockdown suppresses proliferation and induces apoptosis by regulating miR-148b/WNT/ $\beta$-catenin in ox-LDL -stimulated vascular smooth muscle cells. Journal of biomedical science. 2018;25(1):11.

47. Saiz-Ladera C, Lara MF, Garin M, Ruiz S, Santos M, Lorz C, García-Escudero R, Martínez-Fernández M, Bravo A, Fernández-Capetillo O, Segrelles C, Paramio JM. p21 suppresses inflammation and tumorigenesis on pRB-deficient stratified epithelia. Oncogene. 2014;33(37):4599-612.

48. Zhang A, Shang W, Nie Q, Li T, Li S. Long non-coding RNA H19 suppresses retinoblastoma progression via counteracting miR-17-92 cluster. Journal of cellular biochemistry. 2018;119(4):3497-509.

49. Zamir-Nasta T, Razi M, Shapour H, Malekinejad H. Roles of p21, p53, cyclin D1, CDK-4, estrogen receptor $\alpha$ in aflatoxin B1-induced cytotoxicity in testicular tissue of mice. Environmental toxicology. 2018;33(4):385-95.

50. Liu C, Chen Z, Fang J, Xu A, Zhang W, Wang Z. H19-derived miR-675 contributes to bladder cancer cell proliferation by regulating $\mathrm{p} 53$ activation. Tumour biology. 2016;37(1):263-70.

51. Huang ZW, Tian LH, Yang B, Guo RM. Long noncoding RNA H19 acts as a competing endogenous RNA to mediate CTGF expression by sponging miR-455 in cardiac fibrosis. DNA and cell biology. 2017;36(9):759-66.

52. Giovarelli M, Bucci G, Ramos A, Bordo D, Wilusz CJ, Chen CY, Puppo M, Briata P, Gherzi R. H19 long noncoding RNA controls the mRNA decay promoting function of KSRP. Proceedings of the National Academy of Sciences of the United States of America. 2014;111(47):E5023-8. 


\section{Figure 1}

Cell viability was assessed in RPE cells by using the MTS assay.

(A) ICA treatments exerted an inhibitory effect on RPE cells without stimulation of PDGF-BB. After a series concentration of ICA $(0,1,5,10,20,40$ and $80 \mu \mathrm{M})$ treatments for $48 \mathrm{~h}$, the IC50 value of ICA was calculated using GraphPad Prism 8.0. (B) The cellular proliferating ability was assessed by the proliferation curve at $0,24,48,72$ hours after ICA treatment. Control :

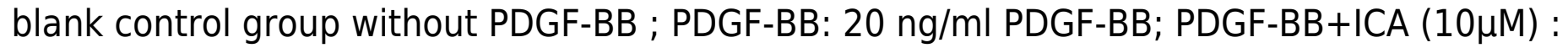

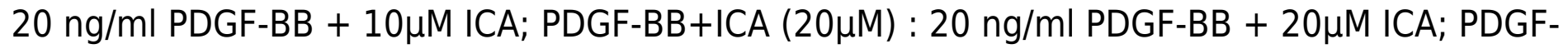
$\mathrm{BB}+\mathrm{ICA}(40 \mu \mathrm{M}): 20 \mathrm{ng} / \mathrm{ml}$ PDGF-BB $+40 \mu \mathrm{M}$ ICA. Data are expressed as mean \pm SD. ${ }^{\# \#} \mathrm{P}<$ 0.001 vs. Control group; ${ }^{*} \mathrm{P}<0.05,{ }^{* *} \mathrm{P}<0.01,{ }^{* * *} \mathrm{P}<0.001$ vs. PDGF-BB group.

A

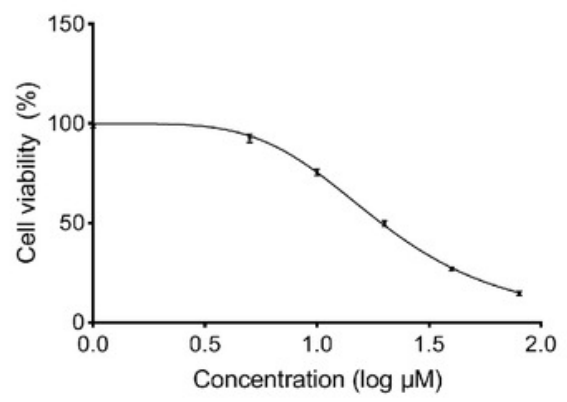

B

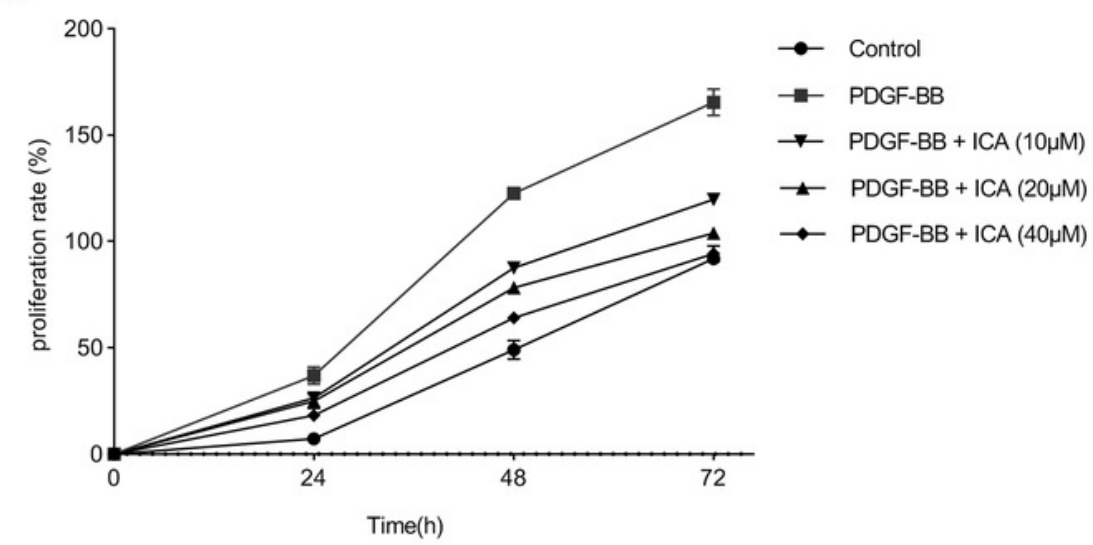


Figure 2

Effects of ICA on the cell cycle progression of PDGF-BB-stimulated RPE cells after $48 \mathrm{~h}$.

Cell cycle was determined by individual nuclear DNA content reflected by fluorescence intensity of incorporated PI. Percentage of cells in G0/G1, S and G2/M phases were calculated. Represent images of cell cycle in (A) Control, (B) PDGF-BB, (C) PDGF-BB+ICA $(10 \mu M)$, (D) PDGF-BB+ICA $(20 \mu M)$ and (E) PDGF-BB+ICA $(40 \mu M)$; (F) Bar graphs show the percentage of cells at each stage. Data are expressed as mean $\pm S D(n=3) .{ }^{\# P}<0.05,{ }^{\# \# P} P$ 0.01 vs. Control group; ${ }^{*} \mathrm{P}<0.05,{ }^{* *} \mathrm{P}<0.01,{ }^{* * *} \mathrm{P}<0.001$ vs. PDGF-BB group.

A

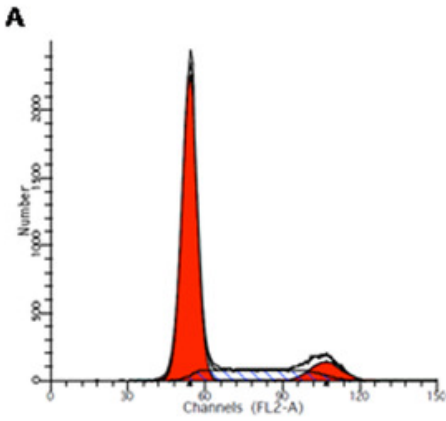

$\mathrm{E}$

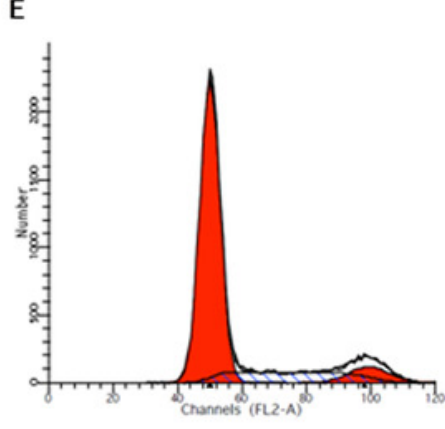

B

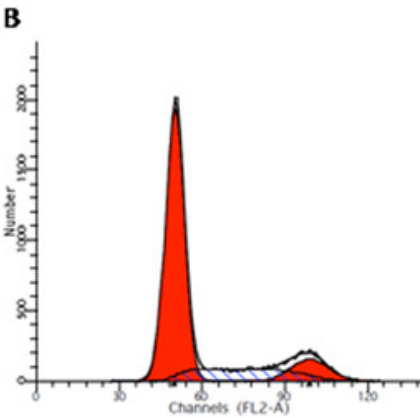

C
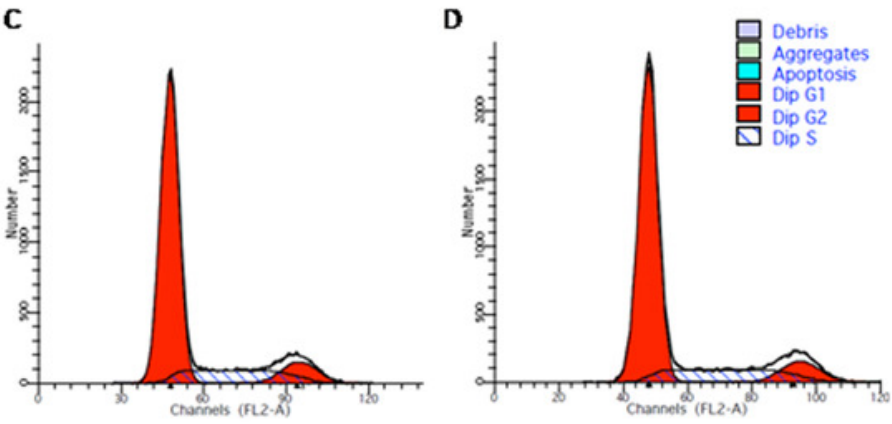

$\mathbf{F}$

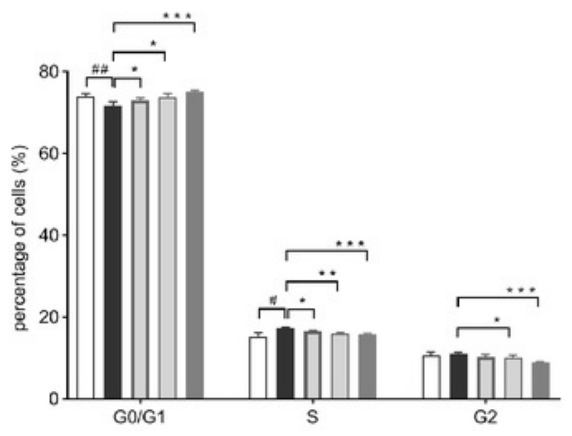

Control

- PDGF-BB

- PDGF-BB + ICA (10MM)

- PDGF-BB + ICA (20MM)

- PDGF-BB+ICA (40MM) 
Figure 3

Effects of ICA on cell cycle-related factors expression in PDGF-BB-stimulated RPE cells.

The mRNA levels of $p 53, p 21, C D K 4, C D K 6$, and cyclin D1 were determined by qPCR (A), and the protein levels of $\mathrm{p} 53, \mathrm{p} 21, \mathrm{CDK} 4, \mathrm{CDK} 6$, and cyclin D1 were detected by western blot assay (B and C). Control: blank control group without PDGF-BB; PDGF-BB: 20 ng/ml PDGF-BB;

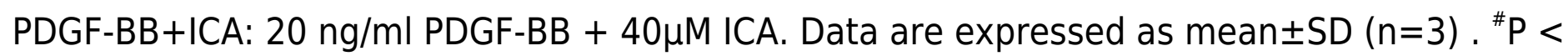
$0.05,{ }^{\# \#} \mathrm{P}<0.01,{ }^{\# \# \#} \mathrm{P}<0.001$ vs. Control group; ${ }^{*} \mathrm{P}<0.05,{ }^{* *} \mathrm{P}<0.01,{ }^{* * * *} \mathrm{P}<0.001$ vs. PDGFBB group.
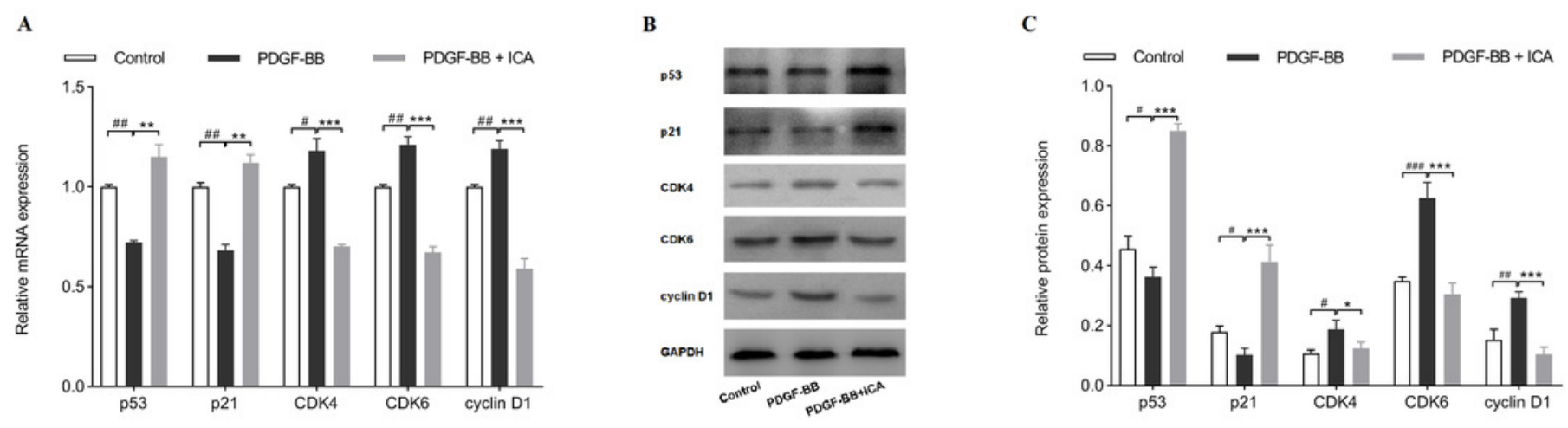
Figure 4

Effects of ICA on PDGF-BB-stimulated H19 expression in RPE cells.

The expression of $\mathrm{H} 19$ as determined by qPCR was decreased by PDGF-BB, but ICA increased

H19 expression depending upon concentrations. Data are expressed as mean \pm SD. ${ }^{\# \#} \mathrm{P}<$ 0.001 vs. Control group; ${ }^{*} \mathrm{P}<0.05,{ }^{* *} \mathrm{P}<0.01,{ }^{* * *} \mathrm{P}<0.001$ vs. PDGF-BB group. 


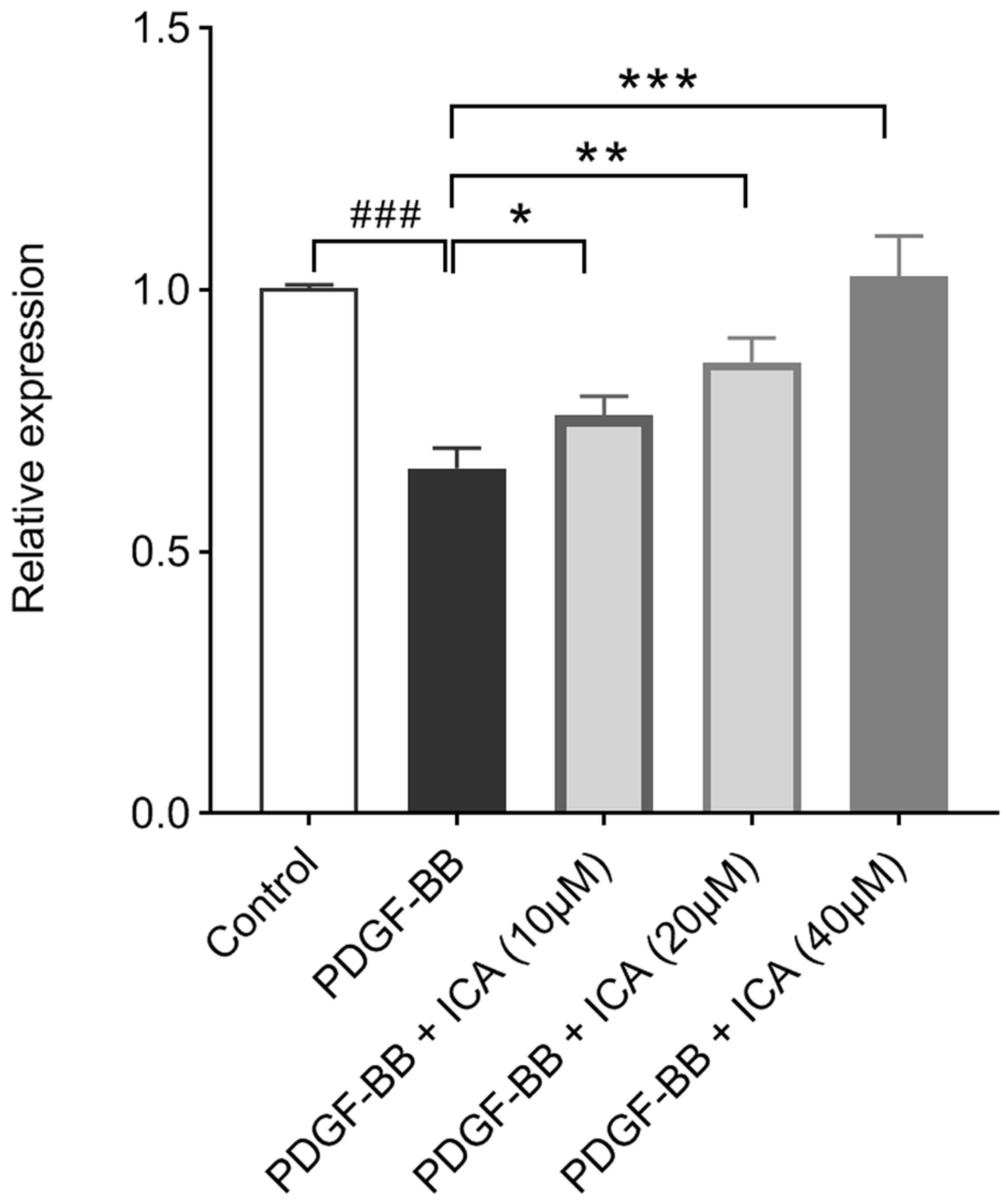




\section{Figure 5}

Down-expression of $\mathrm{H} 19$ reversed ICA-induced cell proliferation in PDGF-BB-stimulated RPE cells.

(A) Transfected efficiency of si-H19 or si-NC on H19 expression was detected by qPCR in RPE cells. (B) Cell proliferation of ICA-treated RPE cells with si-H19 or si-NC transfection was measured by MTS assay at 0, 24, 48, 72 hours. Bar graphs show the OD of all groups. (C) The cellular proliferating ability was assessed by the proliferation curve. (D-H) The distribution of cell cycle in RPE cells with si-H19 or si-NC transfection was assessed by flow cytometry; (D) Control group; (E) PDGF-BB group; (F) PDGF-BB+ICA group; (G) PDGF-BB+ICA+si-NC group; (H) PDGF-BB+ICA+si-H19 group. (I) Bar graphs show the percentage of cells at each stage $(n=3)$. OD, optical density. Control: blank control group without PDGF-BB; PDGF-BB: $20 \mathrm{ng} / \mathrm{ml}$

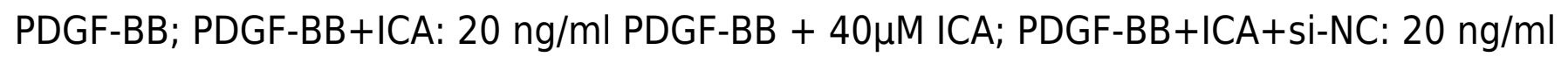

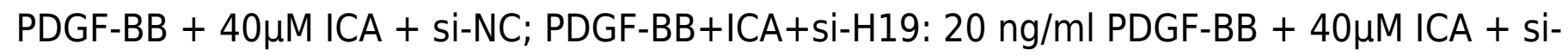
H19. OD, optical density. Data are expressed as mean \pm SD. ${ }^{\# \#} \mathrm{P}<0.001$ vs. Control group; ${ }^{* *} \mathrm{P}<0.01,{ }^{* * *} \mathrm{P}<0.001$ vs. PDGF-BB group; ${ }^{\Delta \mathrm{P}}<0.05,{ }^{\Delta} \mathrm{P}<0.01,{ }^{\Delta \Delta \Delta} \mathrm{P}<0.001$ vs. PDGF$\mathrm{BB}+\mathrm{ICA}+\mathrm{si}-\mathrm{NC}$ group. 
A

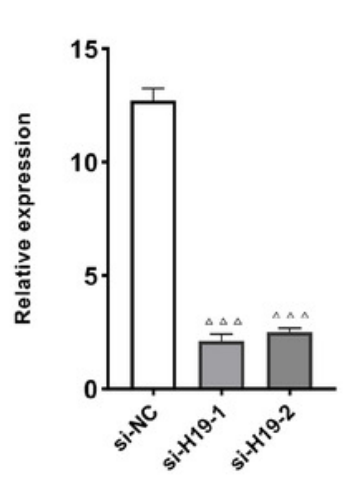

B

$\square$ Control - PDGF-BB $=$ PDGF-BB+ICA

$\succeq$ PDGF-BB+ICA+Si-NC $\square$ PDGF-BB+ICA+si-H19

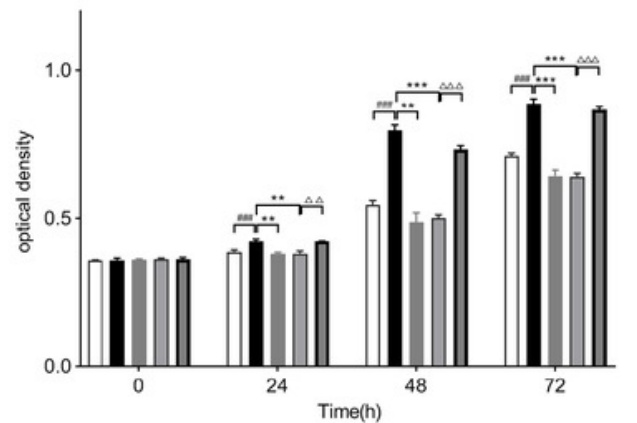

C

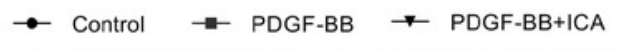

$\leftarrow$ PDGF-BB+ICA+si-NC $\rightarrow$ PDGF-BB+ICA+si-H19

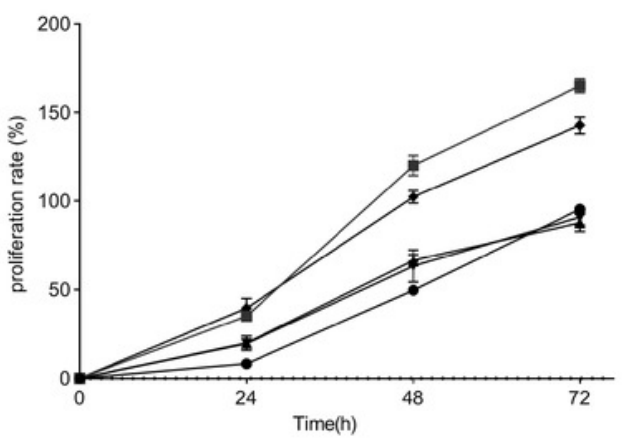

D

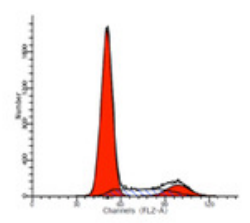

G

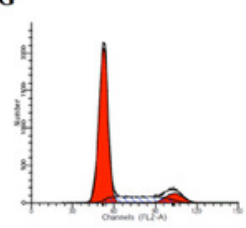

E

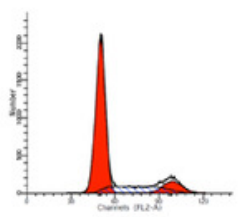

H

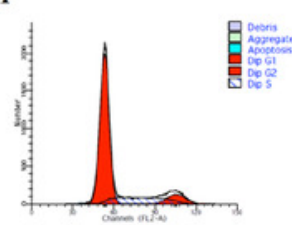

F

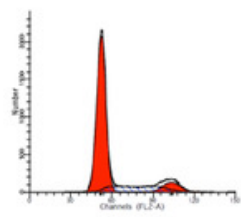

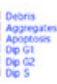

I

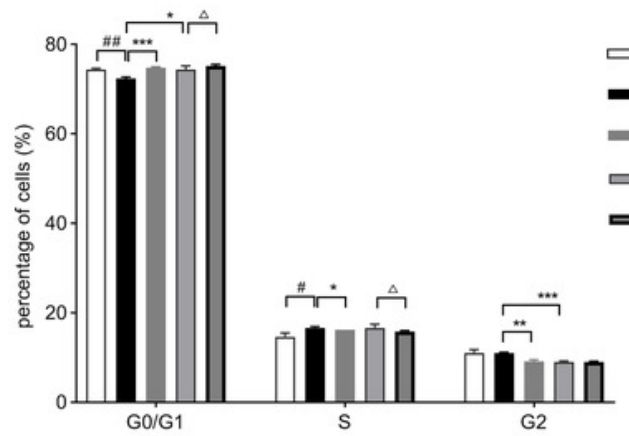


Figure 6

Down-expression of $\mathrm{H} 19$ reversed ICA-induced changes in cell cycle-related factors expression.

The mRNA levels determined by qPCR (A), and the protein levels detected by western blot assay (B and C). Data are expressed as mean $\pm S D(n=3)$. ${ }^{\#} P<0.05,{ }^{\# \#} P<0.01,{ }^{\# \#} P<0.001$ vs. Control group; ${ }^{* *} \mathrm{P}<0.01,{ }^{* * *} \mathrm{P}<0.001$ vs. PDGF-BB group; ${ }^{\Delta \mathrm{P}}<0.05,{ }^{\Delta \Delta} \mathrm{P}<0.01,{ }^{\Delta \triangle \Delta \mathrm{P}}<$ 0.001 vs. PDGF-BB+ICA+si-NC group.

A
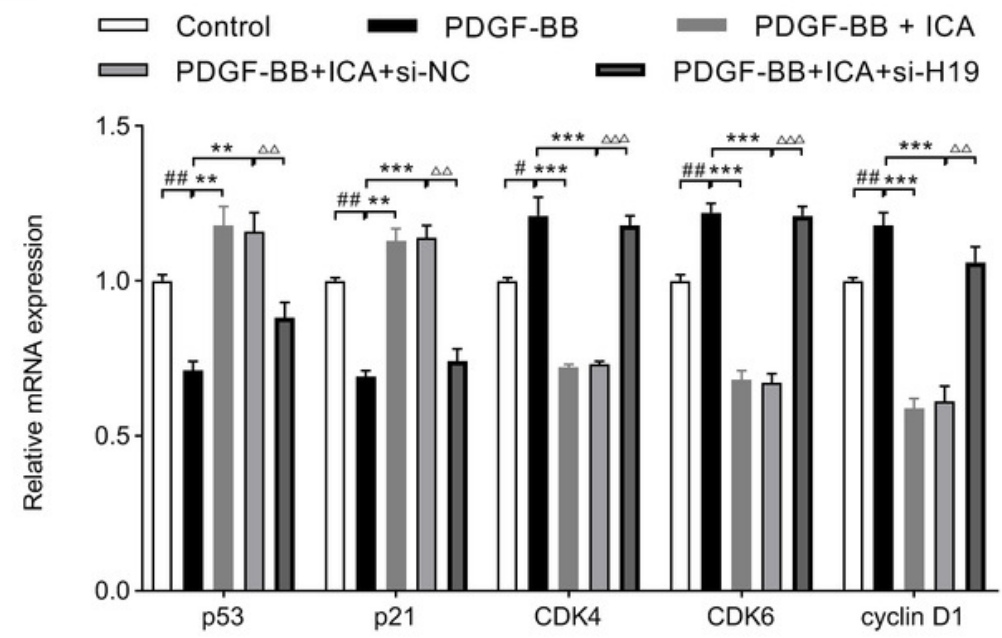

B

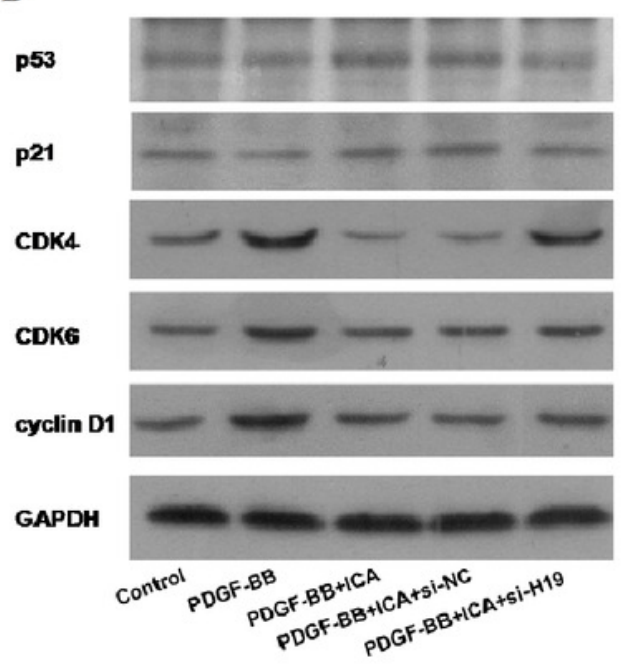

C
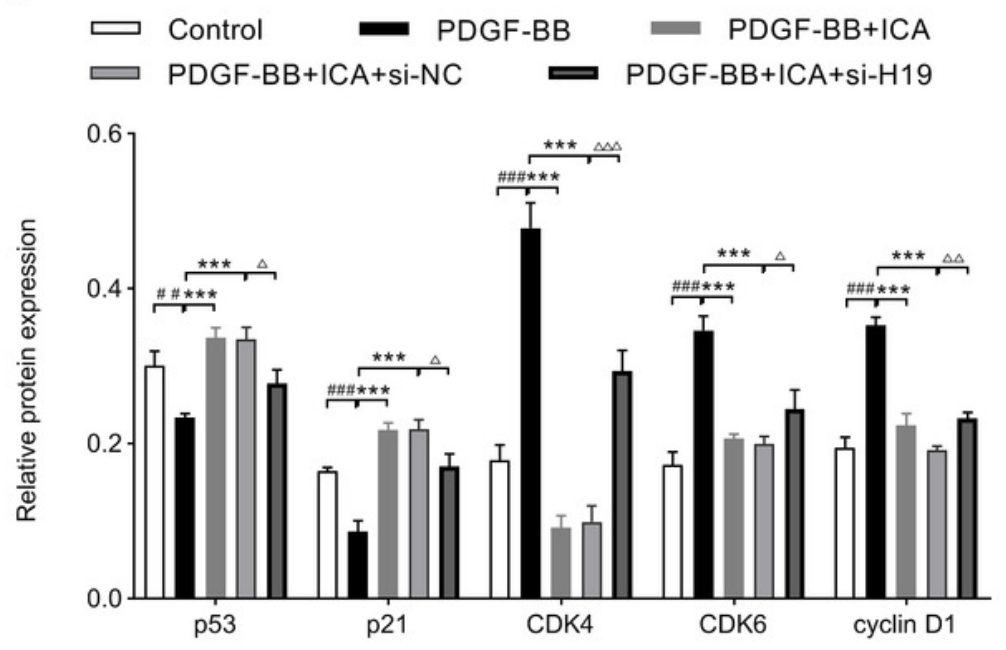
Table $\mathbf{1}$ (on next page)

Primers used for qPCR

Primers used for qPCR 
1 Table 1

\begin{tabular}{ccc}
\hline Gene & Forward primer $\left(5^{\prime}\right.$-3' $\left.^{\prime}\right)$ & Reverse primer $\left(5^{\prime}\right.$-3’ $\left.^{\prime}\right)$ \\
\hline p53 & TAGTGTGGTGGTGCCCTATG & CCAGTGTGATGATGGTGAGG \\
p21 & TGCCCAAGCTCTACCTTCC & CAGGTCCACATGGTCTTCCT \\
CDK4 & ATGTCCGACCTGTTCCACA & CGAAGTCAAAGTTCCACCG \\
CDK6 & ACGTGGTCAGGTTGTTT & TTTATGGTTTCAGTGGG \\
cyclin D1 & CCCGCACGATTTCATTGAAC & AGGGCGGATTGGAAATGAAC \\
H19 & GCGGGTCTGTTTCTTTACTTC & GTGGTTGTAAAGTGCAGCAT \\
\hline
\end{tabular}

2 


\section{Table 2 (on next page)}

Inhibitory effects of ICA with different concentrations on PDGF-BB-stimulated proliferation of RPE cells.

RPE cells proliferation was determined with MTS assay at 24, 48, 72 hours after ICA treatment. Absorbance at $490 \mathrm{~nm}$ shows that ICA obviously inhibited PDGF-BB-stimulated proliferation of RPE cells in a concentration dependent manner. The IC50 values of ICA in RPE cells were $30.13 \mu \mathrm{M}$ at $24 \mathrm{~h}$ and $12.53 \mu \mathrm{M}$ at $48 \mathrm{~h}$. Control: blank control group without PDGF-

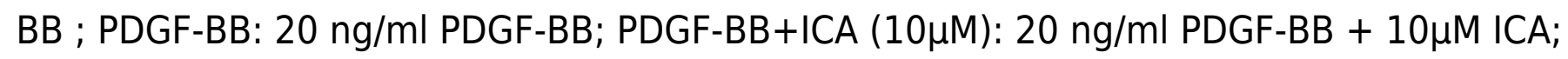

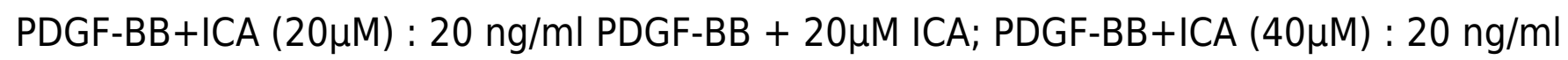
PDGF-BB $+40 \mu \mathrm{M}$ ICA. Data are expressed as mean \pm SD. ${ }^{\# \# \# P}<0.001$ vs. Control group; ${ }^{*} \mathrm{P}<$ $0.05,{ }^{* *} \mathrm{P}<0.01,{ }^{* * *} \mathrm{P}<0.001$ vs. PDGF-BB group; ${ }^{\Delta \mathrm{P}}<0.05,{ }^{\Delta \Delta} \mathrm{P}<0.01,{ }^{\Delta \triangle \Delta} \mathrm{P}<0.001$ vs. 20

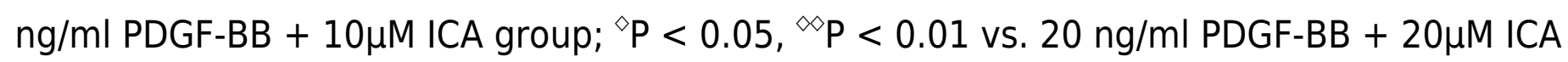
group. 
1 Table 2:

\begin{tabular}{|c|c|c|c|c|c|c|}
\hline \multirow{2}{*}{ Group } & \multicolumn{2}{|c|}{$24 \mathrm{~h}$} & \multicolumn{2}{|c|}{$48 \mathrm{~h}$} & \multicolumn{2}{|c|}{$72 \mathrm{~h}$} \\
\hline & Absorbance & Inhibition (\%) & Absorbance & Inhibition (\%) & Absorbance & Inhibition (\%) \\
\hline Control & $0.38 \pm 0.01$ & & $0.53 \pm 0.02$ & & $0.69 \pm 0.01$ & \\
\hline PDGF-BB & $0.48 \pm 0.01^{\# \# \#}$ & & $0.78 \pm 0.01^{\# \# \#}$ & & $0.94 \pm 0.02^{\# \#}$ & \\
\hline PDGF-BB + ICA $(10 \mu \mathrm{M})$ & $0.45 \pm 0.01^{*}$ & 28.53 & $0.67 \pm 0.01^{* * *}$ & 43.88 & $0.77 \pm 0.01^{* * *}$ & 64.26 \\
\hline PDGF-BB + ICA $(20 \mu \mathrm{M})$ & $0.44 \pm 0.01^{*}$ & 40.28 & $0.63 \pm 0.01^{* * *} \triangle \triangle$ & 60.62 & $0.72 \pm 0.01^{* * *} \triangle \triangle \triangle$ & 86.40 \\
\hline PDGF-BB + ICA $(40 \mu \mathrm{M})$ & $0.43 \pm 0.01^{* *} \triangle$ & 55.93 & $\begin{array}{c}0.59 \pm 0.01^{* * *} \Delta \Delta \triangle \\
\diamond \diamond\end{array}$ & 76.37 & $\begin{array}{c}0.68 \pm 0.01^{* * *} \Delta \Delta \triangle \\
\diamond\end{array}$ & 99.97 \\
\hline
\end{tabular}

2 